\title{
Editorial
}

\section{Thalamic DBS and neuropathic pain}

Robert J. Coffey, M.D.

\section{Thousand Oaks, California}

Pereira and colleagues present a well-documented case series of patients treated using thalamic deep brain stimulation (DBS) to treat pain that arose from two very different kinds of neurological injuries: preganglionic brachial plexus avulsion (BPA) and phantom limb pain consequent to peripheral nerve injuries after limb amputation. ${ }^{6}$ To the authors' credit, they briefly discuss the apparent contradiction between the published findings of single-institution case series, including their own, and the decisions of DBS device manufacturers not to pursue clinical trials towards US FDA approval for pain. The European CE mark for DBS, which permits use (and health insurance payment) for treatment of disorders that are not approved in the US, is based on publications and statements from dedicated practitioners, not on the results of controlled trials. Moreover, US FDA approvals for other neurostimulation modalities to treat chronic pain (except DBS) were "grandfathered in" in the 1980s, also on the basis of dedicated practitioner testimony and early publications, but without formal clinical trial evidence. The other interesting difference is between dedicated authors' interpretation of published results for neurostimulation (and other device-based) pain modalities compared with skeptical or regulatory-style analyses, which has been addressed elsewhere, and is outside the scope of this Neurosurgical Focus issue. ${ }^{1-4}$

Selected features of the present DBS article still bear notice by way of analysis and interpretation. For example, this is the second article in 2 years that this reviewer has commented on, and in which authors chose to state their conclusions in the article's title. A 2011 article in another journal, "Spinal cord stimulation is effective in management of complex regional pain syndrome I: fact or fiction" elicited "fiction" as this reviewer's well-considered assessment, made in a comment that accompanied the published article ${ }^{5}$ Regarding the present article, ${ }^{6}$ its title as submitted was "Thalamic deep brain stimulation relieves neuropathic pain after amputation or brachial plexus avulsion"-which the editorial office revised according to a policy that allows only descriptive titles. However, by any other name, the limitations, errors, and flaws in this article remain the same. ${ }^{6}$ Readers should bear in mind that such articles may describe consecutive patient series, and may have involved a prospective plan, but do not represent a comprehensive series of all patients treated using DBS or whichever stimulation modality is under discussion. In this sense, this and other articles may be viewed as single-institution responder analyses, subject to inherent biases when the author-investigators select the patients, treat the patients, and (despite having quasi-independent individuals fill out follow-up forms) interpret, analyze, and publish the results. For example, BPA and peripheral nerve injuries with phantom pain arise from different mechanisms and situations. Plexus avulsion customarily involves massive blunt trauma and leaves visible lozenge-shaped pits in the dorsolateral sulcus of the spinal cord, whereas limb amputation can result from blunt, sharp, or penetrating missile trauma, or result from surgery for nontraumatic conditions. Despite having similar pain description phenotypes, underlying mechanisms and other features of these two conditions differ. What the two groups share are reportedly salutary results. One does not know, as a hypothetical example, whether or how many patients with peripheral nerve injuries not associated with amputation may have been treated using DBS during the same interval, and with what degree of success. Again, these observations are characteristic of the DBS and pain literature in general, and are not particular to the present article, and do not make it subject to individual criticism.

Finally, the authors (and another reviewer) addressed the divergence between the beneficial pain outcomes observed in this series versus the lesser effects reported for physical and social secondary outcomes. Such findings are unusual, not because of divergence, but because analgesic efficacy in US-based interventional pain studies tends to lag behind physical, social, and global satisfaction measures. In this study, it is the other way around. Attributing the primary versus secondary outcomes reversal to differences in national culture and health care delivery systems admittedly adds little to our understanding. But such differences may matter when attempting to harmonize larger, pivotal, or industry-sponsored clinical trial results across international boundaries for other psychobehavioral disorders as well as for chronic pain. (http://thejns.org/doi/abs/10.3171/2013.7.FOCUS13275)

\section{Disclosure}

The author is an employee of Medtronic, Inc. 


\section{References}

1. Coffey RJ: Deep brain stimulation for chronic pain: the results of two multi-center trials and a structured review. Pain Med 2:183-192, 2001

2. Coffey RJ: Evidence, the practice of pain surgery, and the Institute of Medicine report, in Burchiel K (ed): Surgical Management of Pain, ed 2. New York: Thieme, 2014 [in press]

3. Coffey RJ, Hamani C, Lozano AM: Evidence base: neurostimulation for pain, in Winn HR (ed): Youmans Neurological Surgery, ed 6. Philadelphia: Elsevier, 2011, pp 1821-1824

4. Coffey RJ, Lozano AM: Neurostimulation for chronic noncancer pain: an evaluation of clinical evidence, and recommendations for future trial designs. J Neurosurg 105:175-189, 2006

5. Kumar K, Rizvi S, Bnurs SB: Spinal cord stimulation is effective in management of complex regional pain syndrome I: fact or fiction. Neurosurgery 69:566-579, 2011

6. Pereira EAC, Boccard SG, Linhares P, Chamadoira C, Rosas MJ, Abreu P, et al: Thalamic deep brain stimulation for neuropathic pain after amputation or brachial plexus avulsion. Neurosurg Focus 35(3):E7, 2013

\section{Response}

Erlick A. C. Pereira, D.M., ${ }^{1}$ Rui Vaz, M.D., Ph.D., ${ }^{2}$ And Tipu Z. AzIz, F.Med.ScI. ${ }^{1,2}$

${ }^{1}$ Department of Neurosurgery, Oxford University Hospitals, Oxford, United Kingdom; and ${ }^{2}$ Department of Neurosurgery, Hospital de São João, University of Porto, Portugal

Deep brain stimulation and indeed neurosurgery for chronic pain present great challenges discussed elsewhere in this dedicated issue and the reviews cited by Dr. Coffey in his editorial that accompanies our case series. Among such challenges are patients, with pain refractory to pharmacotherapy, who often present after other failed pain neurosurgeries, and a lack of objective biomarkers for chronic pain to guide outcomes assessment at the bedside. Clinical practice has advanced ahead of other neurosurgical subspecialties and surgeons in general over the last two decades to regularly include patient-reported outcome measures with quality of life assessments in most published case series, including our own. Nevertheless, the leap from a case series to a well-designed, randomized controlled trial (RCT) remains a Herculean one.

Aside from RCT issues of funding, recruitment, and follow-up, the power such studies have to detect a difference between groups relies upon setting a meaningful threshold of clinical improvement with a ratified outcome score. Historically, 50\% improvement in a total pain score has been used, but such sustained quantitative improvements are unusual in populations of patients whose chronic pain waxes and wanes, and may be ameliorated by therapy in some qualitative components of pain more than others. Alternative thresholds and approaches to study design are therefore desirable alongside the holy grail of an objectively measurable biomarker for chronic pain.

In surgery, Oxford's IDEAL (Idea, Development, Exploration, Assessment, Long-term Study) collaboration has advocated a number of study types as more suitable to delivering high-class evidence-based surgery. ${ }^{6,7}$
These study types include rigorously studied contiguous case series in which both detailed technique and surgeon learning curve are described and comprehensive results presented. ${ }^{3}$ Furthermore, DBS can be reversed (switched off), with the patient blinded to device status, enabling the same patient to be tested both off and on DBS in contiguous randomly ordered pairs of trials. This so-called "Nof-1" trial paradigm was developed to assess the efficacy of analgesic medications and appears ideal to assessing DBS for pain..$^{5,11}$ In addition, novel paradigms such as "signal to noise" analysis compare the natural history of a condition without treatment to the speed of onset of an efficacious therapy. ${ }^{4}$ These developments in evidence-based surgery advance beyond the narrow-minded dogmas of evidence-based medicine (EBM) paradigms that appear conjoined to RCTs, often powered to large numbers of patients to detect small differences between subtly different medications.

Despite the exciting advances in evidence-based surgery mentioned above, the Kuhnian paradigm shift is yet to occur. Most physicians, scientists, and statisticians who chair grant-awarding bodies remain ensconced in RCTs. They are also influenced by the failed multicenter prospective studies of DBS for pain of the 1990s that Dr. Coffey so eloquently reviews in his citations, and the problems outlined above in conducting RCTs in chronic pain populations. It is worth noting that European CE marks are granted on the basis of safety rather than efficacy, and FDA approval has been given to DBS for other nonmovement disorders and spinal cord stimulation for pain on the basis of variable standards of clinical evidence, not all of which convincingly present RCTs that satisfy first-class EBM.

Often a more pragmatic approach is needed to satisfy the desires of neurosurgeons to deliver therapies of demonstrated efficacy in their hands to needy patients. Both surgeons and patients should remain entitled to make an informed choice regarding the benefits and risks of a procedure for an individual person based on the available information, their experience, and their interpretation of the evidence, rather than let guidelines that may crudely summarize flawed evidence dictate practice. The National Institute for Health and Care Excellence recently took an enlightened approach by conducting qualitative research to independently interview both patients and neurosurgeons before deciding to approve DBS for pain in the United Kingdom. ${ }^{9}$ Such novel approaches by funding bodies for clinical trials and health care services alike are needed if we are to reduce the burden of conditions whose severity and scarcity of evidence for effective treatment makes them less easy to justify investing according to traditional perspectives.

As with many other neurosurgical pain treatments described in this issue, there have been no good RCTs for DBS for pain. There is therefore no high-quality evidence to refute the assertion that DBS for pain is effective; the same applies to motor cortex stimulation (MCS). That MCS does not work well in our hands compared with DBS is a personal experience and we would therefore be doing our patients an injustice by offering them MCS. ${ }^{8}$ Therein lies the problem-that surgery is a craft 


\section{Editorial}

that limits the generalizability of RCTs and EBM. We cannot overstate the importance of individual experience and expertise and studying one's outcomes. We agree that our experience is not a typical microcosm of the Gestalt experience of DBS for pain by all surgeons for all causes. Amalgamating and attempting to draw meaningful conclusions from such a disparate literature is an almost futile exercise that both we and Dr. Coffey have tried, ,2,10 not least for the heterogeneous outcome measures (if any) used by different practitioners, and for the reasons above. Yet our paper shows that the treatment is not just a singlecenter phenomenon, but that it can be popularized using visiting expertise without changing local techniques, conferring the pleasant surprise of better results than the original center!

We suggest here that DBS works well to relieve pain up to 1 year in patients with chronic pain after traumatic limb injury. We agree that central neuropathic mechanisms are different between amputation and brachial plexus injury, but chose to select such patients in Porto while drawing upon the experience in Oxford of success with those particular patient groups. ${ }^{1}$ We cannot yet explain the phenomenon of pain relief improving to a greater extent than quality of life in these patients, other than to observe cultural differences and speculate upon the effect of severe trauma on subsequent quality of life, both physical and in terms of its psychological sequelae.

The first author has been awarded the AANS William H. Sweet and CNS Ronald R. Tasker awards for different case series of DBS for pain in the last 18 months, suggesting a current appetite for the therapy among US neurosurgeons. We are passionate and enthusiastic about investing time and energy both in elucidating the mechanisms of neuropathic pain pathogenesis and DBS differential efficacy in some outcome measures, but not others. We also seek to develop novel clinical trial paradigms and drive a multicenter RCT of DBS for pain should anyone be interested in funding such endeavors. Similarly, we would be delighted to receive neurosurgeons and pain specialists in both Oxford and Porto to review our methods, or visit them to help deliver this therapy that we find so effective and life transforming in selected patients.

\section{References}

1. Boccard SG, Pereira EA, Moir L, Aziz TZ, Green AL: Longterm outcomes of deep brain stimulation for neuropathic pain. Neurosurgery 72:221-231, 2013

2. Coffey RJ, Hamani C, Lozano AM: Evidence base: neurostimulation for pain, in Winn HR (ed): Youmans Neurological Surgery, ed 6. Philadelphia: Elsevier, 2011, pp 1821-1824

3. Ergina PL, Barkun JS, McCulloch P, Cook JA, Altman DG: IDEAL framework for surgical innovation 2: observational studies in the exploration and assessment stages. BMJ 346: f3011, 2013

4. Glasziou P, Chalmers I, Rawlins M, McCulloch P: When are randomised trials unnecessary? Picking signal from noise. BMJ 334:349-351, 2007

5. Green AL, Shad A, Watson R, Nandi D, Yianni J, Aziz TZ: $\mathrm{N}$-of-1 trials for assessing the efficacy of deep brain stimulation in neuropathic pain. Neuromodulation 7:76-81, 2004

6. McCulloch P, Altman DG, Campbell WB, Flum DR, Glasziou P, Marshall JC, et al: No surgical innovation without evaluation: the IDEAL recommendations. Lancet 374:1105-1112, 2009

7. McCulloch P, Schuller F: Innovation or regulation: IDEAL opportunity for consensus. Lancet 376:1034-1036, 2010

8. Nandi D, Smith H, Owen S, Joint C, Stein J, Aziz T: Periventricular grey stimulation versus motor cortex stimulation for post stroke neuropathic pain. J Clin Neurosci 9:557-561, 2002

9. National Institute for Health and Clinical Excellence: Deep brain stimulation for refractory chronic pain syndromes (excluding headache). London: National Institute for Health and Clinical Excellence, 2011 (http://www.nice.org.uk/nice media/live/12803/53588/53588.pdf) [Accessed July 26, 2013]

10. Pereira EAC, Aziz TZ: Deep brain stimulation, in Hayek S, Levy R, Deer T (eds): Neurostimulation for the Treatment of Chronic Pain. Philadelphia: Saunders, 2011, pp 187-201

11. Sackett DL: Clinician-trialist rounds: 4 . Why not do an N-of-1 RCT? Clin Trials 8:350-352, 2011

Please include this information when citing this paper: DOI: 10.3171/2013.7.FOCUS13275. 